\title{
Telenovela: elementos identitários em vinheta de abertura
}

\section{Jaqueline Esther Schiavoni}

Universidade Estadual Paulista Júlio de Mesquita Filho, São Paulo, SP, Brasil

ORCID: https://orcid.org/0000-0002-1862-6349

\begin{abstract}
Resumo
Considerando que a telenovela permanece como uma das formas culturais de maior interesse por parte do público em nosso país, buscamos explicitar algumas das principais estratégias de apresentação desse tipo de produto na grade de programação. Para tanto, realizamos um levantamento histórico das novelas produzidas e transmitidas pela Rede Globo, emissora brasileira que mais investiu em dramaturgia e cujas obras possuem reconhecida qualidade de produção tanto no país como no exterior. A investigação considerou o período que vai de 1965 a 2015, utilizando como referência os títulos disponíveis no site Memória Globo. Vinhetas de abertura foram analisadas à luz da semiótica francesa, e os resultados apontaram para o reconhecimento de quatro recursos recorrentemente explorados: projeções de pessoa, tempo, espaço e procedimentos de tematização - todos articulados de forma a promover no público um sentido de identificação.
\end{abstract}

\section{Palavras-chave}

Telenovela. Vinheta. Semiótica francesa.

\section{Introdução}

As vinhetas de abertura estão presentes na televisão brasileira desde que essa mídia iniciou suas atividades no país, na década de 1950. Em todo esse tempo, sua presença na telinha nunca foi meramente decorativa. Embora os recursos técnicos utilizados em cada época buscassem encantar os olhos e os ouvidos do público, isso não era um fim em si mesmo: o objetivo era a apresentação do programa a ser exibido, cativando o interesse da audiência. Assim, as vinhetas sempre mantiveram estreita relação com a forma e o conteúdo das atrações anunciadas, promovendo seus elementos identitários mais marcantes (SCHIAVONI, 2015). 
O objetivo deste trabalho é justamente investigar essa relação entre produto e publicidade no âmbito da telenovela, abordando como as características que estruturam produções desse tipo são exploradas em seus respectivos vídeos de abertura - traduzindo, portanto, não apenas os elementos que embasam, em cada caso, o conteúdo da história específica a ser contada, mas também aqueles que fundam o próprio gênero telenovela como forma narrativa. Para isso, realizamos um levantamento histórico das telenovelas transmitidas pela Rede Globo, emissora brasileira que mais investiu em dramaturgia e cujas obras possuem reconhecida qualidade de produção tanto no país como no exterior, a fim de visualizar como a emissora procede ao elaborar suas vinhetas de abertura e que tipo de elementos identitários ela prioriza em se tratando de telenovela.

A investigação considerou o período que vai de 1965 a 2015, isto é, desde a inauguração da Rede Globo até a data em que a emissora completou 50 anos de existência. A abrangência histórica da visada proposta teve por escopo a percepção de possíveis reiterações, ao longo do tempo, no modo como a emissora constrói as vinhetas de abertura em torno do gênero telenovela, avaliando os componentes comuns às diversas produções. Em outros termos, buscamos elementos que nos permitissem reconhecer algum tipo de padrão nos modos de construção dessas narrativas, apesar da variedade de tramas apresentadas em todo esse período, bem como as muitas alterações vividas desde então pela sociedade brasileira.

As peças foram analisadas à luz da semiótica francesa, notadamente o percurso gerativo de sentido desenvolvido por Greimas (1979), segundo o qual todo objeto semiótico pode ser definido conforme o modo de sua produção, um percurso em que o enunciador ou produtor do discurso parte de estruturas mais simples e abstratas e chega a outras mais complexas e concretas:

As estruturas profundas são habitualmente opostas, em semiótica, às estruturas de superfície (ou superficiais): enquanto estas pertencem, por assim dizer, ao domínio do observável, aquelas são consideradas como subjacentes ao enunciado [...] (GREIMAS; COURTÉS, 1979, p. 351).

As estruturas mais profundas são também chamadas de nível sêmionarrativo, compreendendo, portanto, dois momentos diferentes: no primeiro deles, a significação é articulada a partir de uma oposição semântica mínima, sobre a qual se fundamentará todo o discurso; no segundo, tem-se um conjunto de procedimentos encarregados de operar as 
transformações que farão os enunciados desenvolverem-se e a história ser contada de acordo com o sentido preestabelecido na oposição de base; por fim, tais estruturas sêmionarrativas são retomadas e colocadas em discurso, ganhando a superfície ou o domínio do observável. Tais níveis foram concebidos por Greimas em relações de interdependência, cuja homologação é que permite a conversão de uma estrutura em outra. Em vista disso, o percurso gerativo de sentido funciona não apenas como um modelo de produção de discursos, mas também de leitura e interpretação deles. Assim, partiremos do nível de superfície, no qual se encontram as projeções discursivas, a fim de alcançar as estruturas mais profundas sêmionarrativas - enfocando os elementos mais significativos em cada caso para o alcance de nossos objetivos.

\section{Telenovela: características identitárias}

Para dar início às análises, buscamos operacionalizar o processo elegendo um conjunto de amostragem a partir de intervalos regulares de 10 anos, de modo que foi feito o levantamento das vinhetas exibidas em 1965, 1975, 1985, 1995, 2005 e 2015 - conforme as datas de estreia de cada telenovela. Considerando que na televisão, originalmente, "A ideia em torno da vinheta era que ela carregasse nomes, servindo de suporte para a divulgação do programa [...]" (SCHIAVONI, 2015, p. 20), passamos a observar primeiramente os títulos das produções. Vimos emergir, então, quatro tipos específicos de projeções discursivas: (1) actorial, (2) espacial, (3) temporal, (4) temática. A fim de facilitar a percepção acerca da recorrência dessas abordagens e também verificar se algum título não se encaixaria em algum desses quatro padrões encontrados, tabulamos os dados e destacamos cada um desses enfoques com uma cor aleatória: azul para pessoas; verde para lugares; laranja para referências temporais; vermelho para temas. 0 principal cuidado tomado foi em relação à interpretação dos dados. Embora a maioria dos títulos explicitasse com clareza o foco das tramas a serem narradas - como em A moreninha (actorial), América (espacial), Além do tempo (temporal) e Verdades secretas (temática) - uma pequena minoria de títulos nos suscitava dúvidas. Isso nos levou a buscar mais informações sobre os enredos. Trabalho que, por rigor metodológico, acabamos por estender a todas as obras, confirmando a construção do quadro que segue (Quadro 1): 
Quadro 1 - Telenovela - 50 anos - Rede Globo

\begin{tabular}{|c|c|c|c|c|c|}
\hline 1965 & 1975 & 1985 & 1995 & 2005 & 2015 \\
\hline $\begin{array}{l}\text { Ilusões } \\
\text { perdidas }\end{array}$ & Escalada & $\begin{array}{l}\text { Um sonho } \\
\text { a mais }\end{array}$ & $\begin{array}{c}\text { Irmãos } \\
\text { Coragem } \\
2^{a} \text { versão }\end{array}$ & América & $\begin{array}{l}\text { Sete } \\
\text { vidas }\end{array}$ \\
\hline $\begin{array}{c}\text { Rosinha do } \\
\text { sobrado }\end{array}$ & $\begin{array}{l}\text { Gabriela } \\
1^{\underline{a}} \text { versão }\end{array}$ & $\begin{array}{l}\text { A gata } \\
\text { comeu }\end{array}$ & $\begin{array}{l}\text { A próxima } \\
\text { vítima }\end{array}$ & $\begin{array}{l}\text { A lua me } \\
\text { disse }\end{array}$ & Babilônia \\
\hline Marina & Helena & $\begin{array}{l}\text { Roque } \\
\text { santeiro }\end{array}$ & $\begin{array}{c}\text { História de } \\
\text { amor }\end{array}$ & Alma gêmea & $\begin{array}{c}\text { I love } \\
\text { Paraisópolis }\end{array}$ \\
\hline $\begin{array}{l}\text { Pecado de } \\
\text { mulher }\end{array}$ & O noviço & $\begin{array}{c}\text { Ti-ti-ti } \\
1^{\underline{a}} \text { versão }\end{array}$ & Cara \& coroa & Bang bang & $\begin{array}{l}\text { Verdades } \\
\text { secretas }\end{array}$ \\
\hline $\begin{array}{l}\text { Paixão de } \\
\text { outono }\end{array}$ & Bravo! & $\begin{array}{c}\text { De quina } \\
\text { pra lua }\end{array}$ & $\begin{array}{l}\text { Explode } \\
\text { coração }\end{array}$ & Belíssima & $\begin{array}{l}\text { Além do } \\
\text { tempo }\end{array}$ \\
\hline $\begin{array}{l}\text { A moreninha } \\
1^{\underline{a}} \text { versão }\end{array}$ & Senhora & & & & $\begin{array}{l}\text { A regra do } \\
\text { jogo }\end{array}$ \\
\hline 0 ébrio & $\begin{array}{c}\text { A moreninha } \\
2^{\underline{a}} \text { versão }\end{array}$ & & & & \\
\hline $\begin{array}{l}\text { Um rosto de } \\
\text { mulher }\end{array}$ & Cuca legal & & & & \\
\hline Padre Tião & 0 grito & & & & \\
\hline & $\begin{array}{c}\text { Pecado } \\
\text { capital } \\
\text { 1a versão }\end{array}$ & & & & \\
\hline
\end{tabular}

Elaborado pelo autor. Tabela criada a partir de dados fornecido por Globo Comunicações e Participações (2013a).

Legenda: Projeções discursivas destacadas em diferentes cores: azul (actorial); verde (espacial); laranja (temporal); vermelho (temática). 
Embora o Quadro 1 nos permita diferentes tipos de leitura ${ }^{1}$, o ponto para o qual queremos chamar a atenção neste trabalho é que, em todo o período abordado, nenhum título escapou ou ficou de fora dos conjuntos mencionados anteriormente. Vale ressaltar que o resultado obtido aponta apenas para um determinado tipo de ênfase, pois, em geral, as narrativas das telenovelas valem-se de todas as projeções mencionadas para se desenvolverem. Uma vez verificada a existência dessas estratégias recorrentes, passamos a analisar como tais projeções discursivas se realizavam em tempos mais recentes. Para isso, selecionamos quatro vinhetas de telenovelas que estrearam em 2015, data em que a Rede Globo completou 50 anos de existência. A escolha das peças deu-se de modo aleatório, preservando apenas o requisito de um exemplar para cada estratégia discursiva observada: pessoa, espaço, tempo, tema. Expomos a seguir as análises relativas a cada um desses itens e, ao final, destacamos o que nos pareceu existir como padrão narrativo entre eles.

1 A diferenciação por meio das cores torna evidente, por exemplo, uma mudança de padrão que toma os anos entre 1985 e 1995 como centrais, isto é, como verdadeiros divisores de águas. Assim, deve-se observar que, nas duas primeiras décadas, prevalecem as abordagens em torno de pessoas. Mas, entre 1985 e 1995, a discussão de temáticas aumenta consideravelmente e se sobressai em relação à abordagem actorial. Por fim, nas últimas duas décadas, despontam as ênfases sobre o espaço e o tempo. Diante disso, nos perguntamos o que poderia ter desencadeado tais mudanças nos modos de apresentação das vinhetas e, coerentemente, nas próprias narrativas das telenovelas. Longe de fechar a questão - que pode ser refletida a partir de critérios diversos -, apenas gostaríamos de destacar alguns pontos que, a nosso ver, merecem séria consideração e podem abrir margem para pesquisas futuras. Segundo o historiador Jefferson Balbino, "os anos 1980 foram cruciais [...] pois a sociedade brasileira se encontrava num período de transição e mutação devido ao cenário político que se estabelecia." (2016, p. 5). 0 regime da ditadura militar teve início em $1^{\circ}$ de abril de 1964 e perdurou até 15 de março de 1985, somando 21 anos de intervenção - que correspondem às duas primeiras décadas de atuação da Rede Globo, em cujas novelas predominou a ênfase sobre pessoas, sendo algumas delas provenientes de histórias da literatura brasileira, como em A moreninha (1965/1975 remake) e Senhora (1975). No todo, as principais características desse governo foram o nacionalismo, o desenvolvimentismo e o autoritarismo, com restrições às liberdades civis e a censura sobre os meios de comunicação. Seu auge esteve na década de 70, com o "milagre econômico", e sua decadência no início de 1980, com altos índices de inflação, concentração de renda e pobreza. Tal condição política parece ter sido determinante sobre a ênfase em torno de personagens entre os anos 50 e 70. Já os reflexos da ordem econômica vivida foram sentidos na dramaturgia no período seguinte. Depois do movimento popular por eleições diretas, tiveram início em 1985 os debates para a convocação da Assembleia Nacional Constituinte, responsável pela elaboração de um novo texto constitucional. A Carta Magna foi promulgada em 1988 e o Brasil passou à Nova República, reestabelecendo a democracia. É com o fim da ditadura e início do processo de redemocratização que observamos crescer a quantidade de telenovelas que colocam ênfase sobre temas notadamente contemporâneos. De acordo com Esther Hamburger, "Na segunda metade dos anos 1980, com a transição para a democracia, a Globo realizou seus títulos mais densos, com referências explícitas ao país e comentários sobre decepções e consequências não antecipadas da modernização." (2011, p. 76), o que se refletiu nas vinhetas em títulos como $O$ grito (1975). Esse comportamento pode ser observado até a metade da década de 90, quando há novamente uma mudança de padrão. Nesse novo período, dá-se a popularização da internet, especialmente a partir de 1995, quando surgiu a figura do provedor de rede e as pessoas começaram a ter acesso discado à web, aprofundando a experiência de um mundo interligado. Desde então, a exploração do espaço passou a ser mais recorrente nas vinhetas das telenovelas, projetando, inclusive, espaços internacionais, como em América (2005), Negócio da China (2008) e Caminho das Índias (2009). Antes da popularização da internet, as iniciativas que haviam nesse sentido projetavam ou uma concepção espiritualista-filosófica de espaço, como em A viagem (1994), ou se voltavam para o próprio território nacional, como em Selva de pedra (1972/1986 remake) e Pátria minha (1994). A popularização da internet também parece ter tido efeito sobre as projeções temporais, não somente por conta do encurtamento entre os espaços a partir do acesso a territórios e culturas longínquas em apenas alguns segundos, mas também em resultado da migração de conteúdos para a rede e o processo de convergência digital, ensejando reflexões sobre uma nova época - como em Geração Brasil (2014) - cujas particularidades, às vezes, podem ser melhor percebidas a partir do revivalismo (neste caso, telenovelas em que há a predisposição ou intenção de reviver estilos, formas e ideias que pertenciam ao passado), como em Boogie oogie (2014). 


\subsection{Pessoa}

Para abordar a estratégia em torno de pessoas, utilizaremos a abertura da telenovela Sete vidas, exibida entre março e julho de 2015, no horário das 18h. Nessa vinheta, foram encontradas aproximadamente 100 diferentes sequências de imagens, sobre as quais tentaremos empreender uma análise a partir de seus planos figurativos.

Para dar início à interpretação desse amplo conjunto, destacamos que figuras como as de algodão doce, pipoca, rabiscos de giz e cabeleira de palhaço podem nos levar ao tema infância. Outras, como as de skate e violão, ao tema adolescência. Por fim, figuras como as de chapéus de formatura e motocicleta, ao tema adulto, caracterizado pelo alcance da maioridade. No conjunto que formam, tais imagens transmitem na vinheta a ideia de passagem temporal e de desenvolvimento humano.

Direcionando essas construções imagéticas, a música de abertura da vinheta - What a wonderful world, interpretada por Tiago Iorc - atrela a configuração de um mundo maravilhoso justamente ao acompanhamento desse desenvolvimento do ser humano ao longo do tempo, isto é, ao ato de se "ouvir o choro de bebês e vê-los crescer" (no original, "I hear babies cry and I watch them grow"). Esse desponta, portanto, como um objeto de valor a ser perseguido. Evidentemente, não é o único. Conforme abordado na canção, "observar o verde das árvores e o desabrochar das flores" (no original, "trees of green and red roses too/I watch them bloom for me and you/And I think to myself what a wonderful world"), assim como "contemplar o azul do céu, o branco das nuvens, o brilho do dia e o escuro da noite" (no original, "I see skies of blue and clouds of white/And the brightness of the day/I like the dark/And I think to myself what a wonderful world") são gestos que também integram a percepção de como o mundo é maravilhoso. Mas, seguindo a descrição da trama da novela no site Memória Globo, o primeiro item mencionado é o que ainda está em falta para o personagem Miguel (Domingos Montagner), que no passado foi um doador de sêmen.

No vídeo, outras figuras como as de uma caneca de leite com café sobre a mesa, um ferro de passar roupa e a de um sabonete na área de banho acenam para ao menos dois temas: o do cotidiano, que envolve um conjunto de pequenas ações a serem realizadas por alguém todos os dias, continuamente; e o tema doméstico, uma vez que todas essas composições retratam cenas da vida privada. Tendo em vista que as imagens são sempre polissêmicas, muitas leituras podem ser feitas a partir dessas figuras e temas. Uma delas, ligada ao desenvolvimento humano que abordamos há pouco, diz respeito às tarefas que a 
criação de filhos demanda, como alimentar, vestir, limpar - delineando uma postura ativa para a expressão "ouvir o choro de bebês e vê-los crescer". Uma segunda leitura, ligada à passagem temporal, gira em torno do quanto esses pequenos gestos, somados a outros de outras ordens, podem conduzir à formação de diferentes tipos de adultos. Esse viés é reforçado na vinheta a partir de figuras que retratam pessoas em diversos tipos de cenários: no meio do mato, no meio do trânsito, no meio da água.

Percebemos também que, em diversos quadros, há a utilização figurativa da água. São gotas, poças, piscinas, lagos, rios, etc. Como se sabe, a vida não somente começa na água como depende dela para se desenvolver. Assim, tais figuras nos encaminham para o tema vida. Mas, figuras como a de espermatozoides em vidro e um banco de sêmen nos conduzem para um tipo específico de concepção, a inseminação artificial. Essas imagens revelam o laço natural que ligará, na história, diferentes tipos de pessoas, criadas por famílias diferentes, em lugares diferentes - conforme abordamos no parágrafo anterior -, articulando na narrativa a oposição de base natureza vs. cultura.

Em todo o vídeo são dispostas imagens de pessoas em movimento, caminhando, subindo escadas, pedalando bicicleta, viajando de avião, dirigindo motocicleta, andando de carro. Essas imagens também nos permitem depreender diferentes tipos de sujeitos, visto que identificamos tipos masculinos e femininos. Mas, além disso, elas expressam, ao mesmo tempo, tanto uma ação por parte desses sujeitos, própria do fato de estarem em movimento, como uma busca, visto que implicam um lugar ao qual se quer chegar, um objetivo a ser conquistado, apresentando esses diferentes sujeitos - que integram as sete vidas especificadas no título da vinheta e explicitadas nas imagens de abertura - como o sujeito do fazer da narrativa do vídeo.

Esse sentido está de acordo com a resenha exibida no site Memória Globo, em que lemos: "a trama revela a busca de sete filhos pelo mesmo pai biológico, Miguel (Domingos Montagner), um doador de sêmen" (2017a). Este personagem é descrito como alguém que "foge de vínculos afetivos em função de um trauma familiar, mas é resgatado do exílio emocional pelos filhos biológicos e por Lígia" (GLOBO COMUNICAÇÕES E PARTICIPAÇÕES, 2017b, doc. não paginado) (mãe do bebê Joaquim, o sétimo filho de Miguel, concebido não por inseminação artificial, mas como fruto do relacionamento entre o casal). Tal estrutura narrativa pode então ser descrita a partir do modelo greimasiano do seguinte modo: 


$$
\begin{array}{ll}
\mathrm{PN}=\left[\mathrm{S}_{1} \rightarrow\left(\mathrm{S}_{2} \cap \mathrm{O}_{\mathrm{v}}\right)\right], \text { em que: } & \mathrm{PN}=\text { Programa narrativo } \\
& \mathrm{S}_{1}=\text { Sujeito do fazer/pessoas (sete vidas) } \\
& \mathrm{S}_{2}=\text { Sujeito de estado/pai biológico (Miguel) } \\
& \mathrm{O}_{\mathrm{v}}=\text { Objeto de valor/paternidade afetiva }
\end{array}
$$

Com isso, observamos que nessa vinheta as projeções discursivas buscam colocar em evidência as sete vidas ou pessoas que cumprem na narrativa o papel de sujeito do fazer, sujeitos que seguem em direção à natureza e estipulam o laço natural que os une como um valor axiológico positivo, deixando para trás ou minimizando suas diferenças culturais. É digno de nota que não apareça nas imagens a fisionomia das pessoas retratadas, apenas partes de seus corpos. Essa construção visual cria a noção de genérico em vez de específico, facilitando a identificação do público, que pode projetar-se sobre alguma dessas diferentes formas de vida retratadas.

\subsection{Espaço}

A vinheta escolhida para representar a estratégia da projeção espacial é a da novela $I$ love Paraisópolis, exibida entre maio e junho de 2015, no horário das $19 \mathrm{~h}$. Na peça, chama a atenção as diferentes cores que marcam o plano de fundo em cada quadro: rosa, amarelo, vermelho, azul e laranja. São tons vivos e sólidos, que se intercalam e se repetem na vinheta, expondo em primeiro plano diferentes tipos de figuras. Por conta disso, separamos os frames por cores e, embora tenhamos realizado a análise de cada um deles, concentraremonos em apresentar apenas o conjunto de figuras em fundo "amarelo", visto que são essas que estabelecem relação com a imagem final do vídeo - o cartaz da vinheta - em que lemos: I love Paraisópolis.

Nesse conjunto cromático estão figuras como as de motociclistas em motos robustas; uma réplica da estátua da liberdade e carros em processo de desmanche (separação de peças). Visto que nas imagens as motos carregam apenas uma pessoa; a estátua da liberdade, com as leis constitucionais dos Estados Unidos nos braços, simboliza a separação e autonomia das treze colônias em relação à Inglaterra; e o carro passa a ser desmontado, isolando suas partes constituintes, vemos emergir o tema independência. De acordo com dicionários, esse termo indica um estado, condição ou caráter de algo ou de alguém que goza de autonomia, de liberdade com relação a alguém ou algo; também diz respeito ao caráter daquilo ou daquele que não se deixa influenciar; que não adota ideias 
preestabelecidas, não segue as regras e os usos correntes; expressando ausência de relação, de subordinação. Independência também significa boa condição material, bem-estar e prosperidade (OXFORD, 2018; MICHAELIS, 2018). Podemos dizer que todos esses sentidos estão presentes nas imagens destacadas.

Para facilitar a compreensão, detalharemos alguns pontos. No que diz respeito às primeiras acepções mencionadas - liberdade, autonomia e insubordinação -, a figura da motocicleta transmite a ideia de um sujeito livre, que pode se deslocar contra o vento, e não que se prende, por exemplo, a um cinto de segurança. Além disso, a motocicleta permite maior flexibilidade de deslocamento, visto que pode passar por espaços estreitos e possui maior facilidade de manobra que outros veículos automotivos, permitindo maior autonomia no trânsito. Se a própria motocicleta já foi e talvez ainda persista em alguns casos como um símbolo de rebeldia, observa-se nas imagens que há, dentre os motociclistas que circulam para lá e para cá com suas motos, um que, diferentemente dos demais, exibe uma cabeça redonda, sendo que todos os demais exibem uma cabeça quadrada. Inferimos para essa forma a circulação de pessoas com o uso de capacete de proteção, e, para a forma esférica, da cabeça humana desprotegida, em um ato de insubordinação.

Quanto à figura do carro em desmanche, vemos as peças desvincularem-se umas das outras, deixando a forma total carro para dar lugar à forma particular de cada peça, deslocando o valor do todo conjunto para as partes independentes que o compõem. Além disso, o desmanche é comumente associado a práticas irregulares. Embora certos estabelecimentos façam tal serviço amparados na lei, muitos ignoram os requisitos a serem cumpridos e comercializam as peças sem alvará e os registros devidos. No vídeo, o processo pouco profissional que a figura na tela dá a ver a partir de um martelo que bate sobre a parte superior do carro leva-nos ao sentido de uma conduta fora das normas ou procedimentos adequados.

A figura da estátua da liberdade também reúne, em uma única imagem, a ideia de independência, autonomia e insubordinação, visto que, para se estabelecerem como território livre, as trezes colônias precisaram romper com o anterior estado de sujeição que mantinham com a Inglaterra, assegurando, para cada uma delas, suas próprias leis.

Quanto às demais acepções - boa condição material, bem-estar e prosperidade -, o fato de as figuras retratarem motocicletas robustas transmite a ideia de estabilidade e acesso a bens de consumo de qualidade, visto que os sujeitos das imagens usufruem efetivamente desse bem móvel, pois estão andando em uma motocicleta em vez, por 
exemplo, de olhando uma motocicleta. Quanto às peças do veículo desmontado, essas em geral seguem para a comercialização, lícita ou ilícita, resultando em ganhos materiais. Já a estátua da liberdade, localizada em Nova York, é ela própria um símbolo do maior expoente capitalista do mundo atual.

Ao final da vinheta, também em fundo amarelo, aparece o título da novela I love Paraisópolis. Esse quadro é formado por diversas partes, mais precisamente pelo espaço de figura e fundo que acompanha cada letra que forma o nome da novela. Tem-se aí também uma articulação entre todo e parte, mas, nesse caso, o valor reside não nas partes, mas, inversamente, na composição total do quadro. 0 título ganha o centro da tela. Em sua parte frontal, vemos o desenho das letras. Na parte de trás, integrando o espaço da figura do coração presente no nome da novela, estão as diversas peças que o compõem. Assim, os sentidos que emanam das figuras nos demais quadros com fundo amarelo, que valorizam as partes do conjunto, são encarnados nesse - que é o último - quadro da vinheta, explicitando os elementos que despertam no sujeito da frase o seu afeto positivo - pois se fala de amor em relação ao lugar chamado Paraisópolis.

Assim, a narrativa principal pode ser descrita como uma busca por valores que giram em torno da ideia de "independência" - liberdade, autonomia, insubordinação, boa condição material, bem-estar e prosperidade - proporcionada pelo lugar, conjunto de valores com os quais o sujeito se identifica e que o fazem amar Paraisópolis, entrando em um estado de conjunção com o lugar. De acordo com o site Memória Globo (GLOBO COMUNICAÇÕES E PARTICIPAÇÕES, 2013c), esse sujeito em torno de quem gira a trama principal é Mari (Bruna Marquezine), uma jovem "[...] criada na comunidade de Paraisópolis [...] que trabalha desde os 13 anos para ajudar a mãe adotiva" e que, junto com a irmã de criação, "decide viajar para Nova York atrás de uma vida melhor", mas, logo em seguida, "é deportada". Expulsa do território americano, a jovem paulistana é acolhida em Paraisópolis, onde segue sua vida e constitui uma família feliz, conforme o final da trama descrito no site Memória Globo: "os moradores de Paraisópolis comemoram o sucesso do projeto de reurbanização na comunidade. Mari e Benjamin celebram com seus trigêmeos" (GLOBO COMUNICAÇÕES E PARTICIPAÇÕES, 2013c).

A proposta de independência ofertada pelo lugar e com a qual Mari se identifica é estendida na música da vinheta (A cor do Brasil, interpretada por Victor Kreutz) para todo tipo de pessoa: "Negro, branco, pardo, colorido, caucasiano [...] Aceitamos todos, então corre e chega aí [...] a felicidade mora aqui." O lugar do qual se fala não é somente Paraisópolis, é o 
Brasil. Esse sentido pode ser depreendido tanto pela música, que explicita o nome do país em seu refrão, como também pelo fato de que tal som se desenvolve temporalmente no vídeo no mesmo instante em que aparece na tela a figura da comunidade em questão, representada por uma favela. Assim, em última instância, o ideal de independência é um ideal de felicidade que o país pode proporcionar a qualquer pessoa que com ele se identifique, pela simples conjunção com o lugar. Em termos gerais, é possível estruturar a trama que acabamos de abordar da seguinte maneira:

$$
\begin{array}{ll}
\mathrm{PN}=\left[\mathrm{S}_{1} \rightarrow\left(\mathrm{S}_{2} \cap \mathrm{O}_{\mathrm{v}}\right)\right], \text { em que: } & \mathrm{PN}=\text { Programa narrativo } \\
& \mathrm{S}_{1}=\text { Sujeito do fazer/lugar (Paraisópolis/Brasil) } \\
& \mathrm{S}_{2}=\text { Sujeito de estado/"I" (Mari/qualquer pessoa) } \\
& \mathrm{O}_{\mathrm{v}}=\text { Objeto de valor/independência/felicidade }
\end{array}
$$

Assim, na representação da vinheta, o lugar tanto propõe os valores de independência e felicidade, capazes de transformar o estado de qualquer sujeito, como supre sua falta por simples conjunção: basta entrar em conjunção com o lugar para entrar em conjunção com a independência e a felicidade. Sobre as noções de objeto e valor, Greimas (2014) alerta que, apesar de termos a tendência de confundir essas duas noções, dado que "[...] a forma figurativa do objeto cauciona sua realidade de modo que por meio dela o valor se identifica com o objeto desejado" (GREIMAS, 2014, p. 33), as coisas não são tão simples assim:

Quando hoje, por exemplo, em nossa sociedade, alguém age como comprador de um automóvel, não é tanto o veículo como objeto de valor que se quer adquirir, mas, essencialmente, um meio de transporte rápido, substituto moderno do tapete mágico de outrora; o que frequentemente se adquire é também um pouco de prestígio social ou um sentimento de poder mais íntimo. 0 objeto visado não passa, então, de um pretexto, de um local de investimento de valores, um alhures que mediatiza a relação do sujeito consigo mesmo. (GREIMAS, 2014, p. 33).

O objeto - neste caso, Paraisópolis - surge como um "espaço de fixação, um local de reunião circunstancial de determinações-valores" (GREIMAS, 2014, p. 35). A aparente facilidade que se apresenta na vinheta para se conquistar os valores propostos ajuda a criar um efeito de identificação com o público: a transformação do estado do sujeito na trama, operada pelo lugar, pode ser dar com qualquer pessoa no mundo natural em condições 
análogas: desde que ame o Brasil e nele permaneça, a pessoa alcançará os valores de independência e poderá ser feliz.

\subsection{Tempo}

Para abordarmos a projeção temporal, escolhemos a vinheta de abertura da novela Além do tempo, exibida entre julho de 2015 e janeiro de 2016, no horário das 18h. A obra é dividida em duas fases e para cada uma delas há uma vinheta específica. No entanto, não se tratam de produções audiovisuais completamente diferentes. Por compartilharem uma gama de recursos expressivos, depreendemos que apenas exprimem momentos diferentes de um mesmo projeto. Dentre tais recursos, podemos citar a plasticidade construída a partir do ritmo dos movimentos de câmera, a utilização de diferentes planos em um mesmo quadro e o jogo entre opacidade e transparência que constitui as camadas das imagens; também o uso de figuras como a do grão de uva, disposto logo no início das vinhetas, a do papel utilizado como suporte de escritura de uma menção honrosa que recorrentemente aparece ao longo dos dois vídeos e a imagem de uma mesma borboleta nas duas produções. Tais elementos estabelecem vínculos identitários entre as peças.

Já o reconhecimento de que se trata da exploração de momentos diferentes desse mesmo projeto decorre das variações em torno de outros recursos plásticos e figurativos. 0 primeiro a destacar está relacionado ao movimento do grão de uva, que cai ao solo na primeira vinheta e sobe do solo na segunda. Considerando que o grão deve morrer para que uma nova planta germine, podemos estabelecer a seguinte relação semissimbólica: /movimento vertical para baixo/ vs. /movimento vertical para cima/ e /morte/ vs. /vida/. Depreendemos tratar-se então de duas sequências temporais distintas: a primeira, da vida para a morte; a segunda, da morte para a vida. Notamos também que as folhas e os frutos que aparecem na primeira fase são predominantemente verdes, enquanto que na segunda fase as folhas já estão amareladas e os frutos maduros, em tons avermelhados. As características plásticas e figurativas descritas podem nos levar a novas relações: /verde/ vs. /vermelho/ e /imaturo/ vs. /maduro/, que nos remete a um processo temporal ao final do qual se alcança o pleno desenvolvimento. A própria etimologia da palavra "maduro" - do latim matūrus, a, um - expressa a importância da ação do tempo sobre o objeto em questão: "que se produz no bom momento, na hora favorável" (OXFORD, 2018, sem paginação). 
Além disso, nos dois vídeos é recorrente o uso de fotografias de indivíduos, casais e famílias. Apesar das semelhanças que podem ser estabelecidas entre tais nas duas vinhetas - como certos traços fisionômicos, tons de pele e tipos de cabelos - não podemos dizer que sejam exatamente as mesmas pessoas. Nessa linha, destacam-se os diferentes estilos de ornamentos e indumentária utilizados, que nos remetem ao passado no primeiro caso e ao presente no segundo. Outro ponto tem a ver com a noção de representação: se, na primeira vinheta, as imagens são, em grande parte, retratos posados, na segunda observam-se mais registros de pessoas em situações cotidianas. Essa distinção parece acompanhar a trajetória da própria fotografia ao longo do tempo, quer dizer, de seus uso sociais em vista da popularização dos dispositivos de registro; e podemos notar, nessas últimas imagens, um processo de sobremolduração - um quadro dentro de outro -, como se estas cenas fossem uma representação daquelas outras da primeira vinheta. Todos esses aspectos colocam em evidência a questão da temporalidade.

Também quanto ao papel ou certificado de menção honrosa que figura nos dois trabalhos, notamos que, no primeiro caso, sua escritura é realizada em letra manuscrita, sendo possível identificar a data de 1893 e, no segundo, em letra tipográfica, sem menção de qualquer data. Vemos que imagens de campos abertos com construções esparsas figuram nas duas produções, mas com paisagens ligeiramente diferentes, sendo que na primeira despontam apenas alguns trabalhadores e algumas casas modestas sobre a vegetação, e na segunda há a presença de homens em maquinários modernos e figuras de prédios. Isso nos ajuda a interpretar a segunda sequência apresentada como pertencente à atualidade, reforçando a oposição já esboçada entre "passado" vs. "presente". No geral, observamos, na primeira vinheta, uma ênfase sobre o plantio de uvas, com o desenvolvimento das raízes e o aparecimento dos primeiros frutos. Na segunda, o destaque está sobre a colheita dos frutos maduros. Ao final, coerentemente, o título da novela é escrito em verde na primeira fase e em vermelho na segunda, marcando, ao mesmo tempo, a passagem temporal e o processo de maturação dele derivado.

Todas essas transformações empreendidas pelo tempo e que são simbolizadas pela figura de uma borboleta - já que esse animal passa por diversos estágios e metamorfoses ao longo de sua existência - mantêm relação direta com a narrativa da telenovela, construída a partir de uma filosofia espiritualista. Os personagens morrem na primeira fase - que se passa "[...] no século XIX, em Campobello, região que se desenvolve graças à colonização italiana e ao cultivo de uvas, no sul do Brasil." (GLOBO COMUNICAÇõES E 
PARTICIPAÇÕES, 2013d, doc. não paginado), conforme encontramos no site Memória Globo - e retornam muitos anos depois, na segunda fase, "com os mesmos nomes e algumas ligações entre si" (GLOBO COMUNICAÇÕES E PARTICIPAÇÕES, 2013d), oportunidade que têm de não cometerem os mesmos erros do passado, conforme detalhado pela emissora:

\begin{abstract}
Além do tempo conta a história de amor entre Lívia (Alinne Moraes) e Felipe (Rafael Cardoso). Dividida em duas fases, a trama mostra o encontro do casal no século XIX. Ele é de uma família nobre e está de casamento marcado com Melissa (Paolla Oliveira). Lívia é de origem humilde e vive no convento por imposição da mãe, Emília (Ana Beatriz Nogueira). Os dois jovens se conhecem em Campobello - cidade fictícia localizada no sul do país -, iniciam um relacionamento conturbado e têm um fim trágico. Cerca de 150 anos depois, acontece um novo encontro entre Lívia, Felipe e as pessoas que conviveram com eles no passado. Todo têm a chance de consertar os erros cometidos na outra vida. Alguns seguem um novo caminho. Outros não. (GLOBO COMUNICAÇÕES E PARTICIPAÇÕES, 2013d, doc. não paginado).
\end{abstract}

Assim, com base nos elementos trabalhados na vinheta de abertura, a estrutura narrativa dessa telenovela pode ser representada, nos moldes do percurso gerativo de sentido, da seguinte maneira:

$$
\begin{array}{ll}
\mathrm{PN}=\left[\mathrm{S}_{1} \rightarrow\left(\mathrm{S}_{2} \cap \mathrm{O}_{\mathrm{v}}\right)\right], \text { em que: } & \mathrm{PN}=\text { Programa narrativo } \\
& \mathrm{S}_{1}=\text { Sujeito do fazer } / \text { tempo } \\
& \mathrm{S}_{2}=\text { Sujeito de estado } / \text { pessoas } \\
& \mathrm{O}_{\mathrm{v}}=\text { Plenitude (maturidade) }
\end{array}
$$

Conforme a descrição da trama, deve-se notar que o tempo é apresentado como um sujeito do fazer que opera não apenas sobre o casal de protagonistas, Felipe e Lívia - cujo amor, conforme expresso na música da vinheta, sobrevive ao tempo -, mas sobre todos os envolvidos na história: "todos têm a chance de consertar os erros" (GLOBO COMUNICAÇÕES E PARTICIPAÇÕES, 2013d), conforme lemos no site. Esse sentido pode ser depreendido também nas vinhetas, que projetam diferentes sujeitos: indivíduos, casais, famílias inteiras. Tais formas de retratar a história acenam para a abrangência dos tipos humanos que desempenham o sujeito de estado na narrativa e, consequentemente, fazem ampliar as possibilidades de identificação do público. Soma-se a isso outro ponto: visto que o recorte temporal efetuado na novela se estabiliza no presente, o sujeito que acompanha a história vê-se implicado nessa grande trama escrita pelo tempo, pois, como um elemento comum 
tanto à arte como à vida, as transformações que ele opera sobre os personagens ocorrem também sobre o telespectador.

\subsection{Tema}

A projeção de temas é exemplificada com a vinheta de abertura da novela $A$ regra do jogo, exibida entre agosto de 2015 e março de 2016, às 21h. No vídeo, vemos um tabuleiro de xadrez separado entre peças brancas e pretas, dispostas para o combate em lados opostos. Essa visão é possível graças à luz amarelada que irradia do lado esquerdo, onde estão as peças pretas, para o lado direito, onde estão as peças brancas. 0 sentido projetado pela luz é o sentido de leitura da imagem e, consequentemente, da transformação anunciada pela música tema (intitulada Juízo Final, interpretada por Alcione), em que o mal dará lugar para o bem: "0 sol há de brilhar mais uma vez. A luz há de chegar aos corações. Do mal será queimada a semente. 0 amor será eterno novamente. É o juízo final, a história do bem e do mal. Quero ter olhos para ver a maldade desaparecer". Assim, vemos surgir a seguinte oposição de base: mal vs. bem.

Visto que, no lado esquerdo, estão as peças pretas e, à direita, as peças brancas, se seguirmos o trajeto de leitura proposto pela luz é possível estabelecer as seguintes homologações semissimbólicas: /esquerda/ vs. /direita/, /preto/ vs. /branco/ e /mal/ vs. /bem/. 0 plano que dá início à vinheta é feito de cima para baixo. A imagem seguinte é feita de baixo para cima. Iniciada a disputa, a câmera passa a captar as imagens e desloca-se horizontalmente, de uma ponta a outra, no mesmo plano do tabuleiro. A partir das escolhas feitas, as peças movimentam-se sem qualquer influência externa.

Embora a disputa se dê entre um plano superior e um plano inferior, a estabilização da câmera no centro, no nível mesmo em que estão as peças, parece reforçar a autonomia das jogadas, que têm por parâmetro um conjunto de princípios ou regras preestabelecidas que se mantêm ao longo da partida. Observamos que tais princípios são seguidos pelas peças brancas, mas trapaceados pelas peças pretas. É assim, pois, que vemos o deslocamento conforme do cavalo branco (duas casas para frente e uma para o lado) em contraste com os desconformes "rebaixamento e eriçamento de quadrantes do tabuleiro", que têm por finalidade livrar as peças pretas e prejudicar as brancas. Todas essas ações reforçam a oposição fundamental apresentada anteriormente, tematizando a disputa entre o bem e o mal. 
O objetivo é atingir o rei do lado oposto. Quando isso ocorre, vence-se a partida. Na vinheta, o foco recai sobre o rei preto. Essa figura do rei, diferentemente da torre ou do cavalo, remete-nos à ideia de um ser humano que exerce poder sobre outros em um território de extensão variada. De acordo com o site Memória Globo (GLOBO COMUNICAÇÕES E PARTICIPAÇÕES, 2013e), "A regra do jogo narra a história de Romero Rômulo (Alexandre Nero), um bandido que finge ser herói do povo [...] 0 que poucos sabem é que o ex-vereador integra a maior facção criminosa do país [...]" (GLOBO COMUNICAÇÕES E PARTICIPAÇÕES, 2013e, doc. não paginado). É esse, portanto, o rei preto a ser colocado em xeque. Tal expressão indica um ataque sofrido pelo rei, peça principal no jogo de xadrez. Significa que esse rei será colocado em "situação perigosa, arriscada ou difícil" e uma vez confrontado deverá mudar de lugar para se salvar (OXFORD, 2018).

Sobre o jogo de xadrez, Saussure (2004) escreveu: "O valor respectivo das peças depende da sua posição no tabuleiro [...]" (SAUSSURE, 2004, p. 104). Acrescentou ainda que "[...] os valores dependem, sobretudo, de uma convenção imutável: a regra do jogo, que existe antes do início da partida e persiste após cada lance." (SAUSSURE, 2004, p. 104). À convenção citada, no caso da novela, podemos associar os princípios constantes de bem e mal evocados de uma tradição religiosa, a partir da expressão juízo final. 0 fato desses valores serem constantes confere estabilidade tanto para o mal quanto para o bem, reforçando a oposição entre eles. Ao ser confrontado, o personagem figurativizado pelo rei preto deverá mudar de posição. Em termos narrativos, isso significa a transformação do sujeito, sua mudança de um estado a outro.

Sobre a trama principal, encontramos no site Memória Globo: "a regra é salvar" (GLOBO COMUNICAÇÕES E PARTICIPAÇÕES, 2013e). Para entender o que isso significa, a partir da analogia estabelecida com o jogo de xadrez, recorremos novamente às formulações de Saussure:

Numa partida de xadrez, qualquer posição dada tem como característica singular estar libertada de seus antecedentes; é totalmente indiferente que se tenha chegado a ela por um caminho ou por outro [...]; para descrever a posição, é perfeitamente inútil recordar o que ocorreu dez segundos antes. (SAUSSURE, 2004, p. 105).

Assim, o que tem importância é o estado atual das coisas, não os antecedentes. De modo similar, no juízo final, o que vale é a posição que o sujeito passa a assumir: para que 
seja absolvido, sua maldade deverá dar lugar à bondade. Nesse sentido, desconsiderar o estado anterior faz toda a diferença, animando a transformação do sujeito, pois esse não terá de carregar consigo seu histórico mau. Dessa forma, entendemos que, embora a noção acerca do bem e do mal seja uma convenção imutável, o ser humano, como uma das peças do jogo, pode mudar de posição e, com isso, passar a ter um valor diferente. A estrutura narrativa da trama principal pode ser representada da seguinte maneira:

$$
\begin{array}{ll}
\mathrm{PN}=\left[\mathrm{S}_{1} \rightarrow\left(\mathrm{S}_{2} \cap \mathrm{O}_{\mathrm{v}}\right)\right], \text { em que: } & \mathrm{PN}=\text { Programa narrativo } \\
& \mathrm{S}_{1}=\text { Sujeito do fazer/a regra do jogo } \\
& \mathrm{S}_{2}=\text { Sujeito de estado/ser humano } \\
& \mathrm{O}_{\mathrm{v}}=\text { Bem (fim da maldade) }
\end{array}
$$

\section{0 sujeito do fazer e a ação dramática}

Conforme mencionamos no início, os níveis do percurso gerativo de sentido são homologáveis entre si, garantindo a coerência do discurso. Dada a função identitária das vinhetas de abertura, nossa intenção foi tentar depreender características do modus operandi da telenovela como um tipo específico de narrativa a partir dos elementos trabalhados no nível discursivo dessas peças. Em cada caso, foi possível perceber que a projeção destacada - pessoa, espaço, tempo, tema - realizava mais do que um simples papel de ancoragem: desempenhava o papel de sujeito do fazer $\left(S_{1}\right)$, modalizando outros $\left(S_{2}\right)$ a fim de que fossem operadas mudanças de estado sobre estes últimos, isto é, a transformação de base da narrativa ou narrativa principal.

Tal estratégia pode parecer banal à primeira vista. Mas, a um olhar mais detido, revelará um trabalho sobre o que se considera ser o cerne da telenovela como narrativa, isto é, a ação dramática. Essa ideia não é exatamente nova, já havia sido apresentada em 1974 por Raymond Williams ao abordar a telenovela como forma cultural: "uma ação dramatizada dividida em capítulos" (WILLIAMS, 2015, p. 70). Assim, em semiótica, o termo ação pode ser definido como "uma organização sintagmática de atos" (GREIMAS; COURTÉS, 1979, p. 9). E o conceito de ato, como "o que faz ser" (GREIMAS; COURTÉS, 1974, p. 31,) isto é, a relação entre enunciados de fazer e de estados, comentada há pouco. A representação canônica do ato foi formulada e interpretada da seguinte maneira: $F\left[S_{1} \rightarrow 0_{v 1}\right.$ $\left.\left(\mathrm{S}_{2} \cap \mathrm{O}_{\mathrm{v} 2}\right)\right]$ 


\begin{abstract}
A interpretação dessa fórmula é simples: o agir pressupõe a existência de um sujeito e se identifica com a modalidade do "fazer" produzindo um estado (ou uma mudança de estado) formulada com a junção de um objeto com o sujeito (que pode estar ou não em sincretismo com o sujeito do fazer). 0 agir corresponde, portanto, parcialmente à performance e pressupõe uma competência modal, considerada como potencialidade do fazer. Por esse motivo, o ato se definirá como a passagem da competência à performance, sendo essa "passagem" sintaxicamente interpretada como a modalidade do fazer (que é a conversão, ao nível da sintaxe antropomorfa, do conceito de transformação) (GREIMAS; COURTÉS, 1979, p. 32, grifos de Greimas e Courtes).
\end{abstract}

Ainda conforme Greimas e Courtés (1979), aquele que realiza ou sofre o ato é chamado de actante: "Assim, para citar L. Tesnière, a quem se deve o termo, 'actantes são os seres ou as coisas que, a um título qualquer e de um modo qualquer, ainda a título de meros figurantes e da maneira mais passiva possível, participam do processo'." (GREIMAS; COURTÉS, 1979, p. 12). Como se pode observar, o conceito de actante substitui, com vantagem, termos como personagem e dramatis persona, "visto que cobre não só seres humanos, mas também animais, objetos e conceitos" (GREIMAS; COURTÉS, 1979, p. 13).

Todas essas definições nos ajudam a perceber que não somente as pessoas, mas também os lugares, tempos e temas projetados podem desempenhar o papel de actante e, mais precisamente, o de sujeito do fazer - validando ou autorizando a posição que ocupam nas análises apresentadas. No caso das telenovelas, embora não seja detalhado nas vinhetas a especificidade dessas ações, os arranjos nos levam a saber em maior ou menor grau em qual direção a trama deverá se desenvolver ao longo do tempo - isto é, a continuidade da ação dramática, apontada por Williams (2015) como elemento definidor da telenovela como forma cultural -, evidenciando a partir dos actantes envolvidos o contrato norteador da história:

Num sentido muito geral, pode-se entender por contrato o fato de estabelecer, de 'contrair' uma relação intersubjetiva que tem por efeito modificar o estatuto (o ser e/ou parecer) de cada um dos sujeitos em presença. [...] 0 fato é que o estabelecimento da estrutura intersubjetiva é ao mesmo tempo, de um lado, uma abertura sobre o futuro e sobre as possibilidades da ação, e de outro, uma coerção que limita de uma certa forma a liberdade de cada um dos sujeitos. (GREIMAS; COURTÉS, 1974, p. 84).

No que tange à explicitação dos sujeitos, percebemos um esforço, em todos os casos, a fim de favorecer o processo de identificação do público com a trama. Na primeira vinheta, 
havia diferentes formas de vida sobre as quais o telespectador podia se projetar como sujeito do fazer; nas demais, o grau de generalidade mantinha-se à medida que tanto o espaço (Brasil), como o tempo (presente) e os valores abordados (bem vs. mal) eram comuns tanto aos sujeitos de estado das tramas como ao telespectador, potencializando a assunção desse papel por ele na vida real. Segundo José Marques de Melo (1988), o sentimento de identificação foi um dos fatores decisivos para a popularidade da telenovela no país: "[...]os usuários da TV ficaram fascinados com a possibilidade de exercitar a sua fantasia cotidiana através de produções artísticas em que podiam reconhecer-se e ao seu meio ambiente." (MELO, 1988, p. 49). E, como vimos, a estratégia permanece, explicando, em certa medida, o interesse que ainda persiste em torno da telenovela como forma cultural.

\section{Considerações finais}

Demos início a este trabalho apontando a utilização das vinhetas de abertura como instrumentos de promoção dos programas da televisão. Colocando nosso foco sobre a telenovela, observamos, nas produções da Rede Globo - emissora de reconhecimento internacional em se tratando de dramaturgia -, um trabalho orientado, com projeções discursivas sobre pessoas, espaços, tempos e temas.

Passamos a analisar, então, o papel que essas projeções exploradas nas vinhetas de abertura cumpriam nas narrativas representadas. A abordagem feita a partir do instrumental teórico da semiótica francesa posicionou nosso olhar sobre um componente específico da estrutura narrativa: o sujeito do fazer. Esse dado nos conduziu para a continuidade da ação dramática como contrato firmado a partir da explicitação desse actante na trama, e também nos revelou arranjos preocupados em favorecer a identificação por parte do público - o que explica, em certa medida, a força com que tal forma cultural persiste em nossa sociedade.

Os resultados apresentados, evidentemente, não colocam fim às discussões em torno da telenovela como forma cultural - que pode, ou mesmo deve, ser avaliada a partir de diferentes perspectivas teóricas e metodológicas. Mas, acreditamos que este trabalho possa servir de contribuição para os estudos da área à medida que comunica elementos fundamentais para o desenvolvimento da telenovela como gênero narrativo e também da vinheta de abertura como peça promocional, abrindo perspectivas para a produção e para a abordagem teórica desses objetos. 


\section{Financiamento}

Fundação de Amparo à Pesquisa do Estado de São Paulo.

\section{Referências}

BALBINO, J. A identidade social brasileira na teledramaturgia: um estudo sobre a telenovela Vale Tudo. In: XV ENCONTRO REGIONAL DE HISTÓRIA. 100 anos da guerra do contestado historiografia, acervos e fontes. Anais. ISSN 1808-9690. Curitiba: UFPR, 2016.

GLOBO COMUNICAÇÕES E PARTICIPAÇÕES. Memória Globo. [S.l.], 2013a. Disponível em: memoriagloblo.globo.com. Acesso em: 7 dez. 2016.

GLOBO COMUNICAÇÕES E PARTICIPAÇÕES. Memória Globo: Sete vidas. [S.l.], 2013b.

Disponível em: http://memoriaglobo.globo.com/programas/entretenimento/novelas /setevidas.htm. Acesso em: 7 de fev. 2017.

GLOBO COMUNICAÇÕES E PARTICIPAÇÕES. Memória Globo: I love Paraisópolis. [S.l.], 2013c. Disponível em: http://memoriaglobo.globo.com/programas/entretenimento/ novelas/i-paraisopolis/i-paraisopolis-fotos.htm. Acesso em: 7 fev. 2017.

GLOBO COMUNICAÇÕES E PARTICIPAÇÕES. Memória Globo: Além do tempo. [S.l.], 2013d. Disponível em: http://memoriaglobo.globo.com/programas/entretenimento/novelas/alem -do-tempo.htm. Acesso em: 7 fev. 2017.

GLOBO COMUNICAÇÕES E PARTICIPAÇÕES. Memória Globo: A regra do jogo. [S.l.], 2013e. Disponível em: http://memoriaglobo.globo.com/programas/entretenimento/novelas/aregra-do-jogo.htm. Acesso em: 7 fev. 2017.

GREIMAS, Algirdas Julien. Sobre o sentido II: ensaios semióticos. São Paulo: Nankin, 2014.

GREIMAS, Algirdas Julien; COURTÉS, Joseph. Dicionário de semiótica. São Paulo: Cultrix, 1979.

HAMBURGER, E. Telenovelas e interpretações do Brasil. In: Lua Nova, São Paulo, 82:61-86, 2011.

MELO, José Marques de. As telenovelas da Globo. São Paulo: Summus, 1988.

MICHAELIS Dicionário de português. [S.l.]: Editora Melhoramentos, 2017. Disponível em: https://michaelis.uol.com.br. Acesso em: 7 fev. 2017.

OXFORD Dicionário de português. [S.l.]: Oxford University Press, 2018. 1 CD-ROM.

SAUSSURE, Ferdinand de. Curso de linguística geral. São Paulo: Cultrix, 2004. 
SCHIAVONI, Jaqueline Esther. Vinheta de TV: tipos, usos e funções. Bauru: Mediaworks, 2015.

\title{
Soap opera: discursive projection in opening videos
}

\begin{abstract}
Considering that the telenovela remains one of the cultural forms of greater interest by the public in our country, we tried to present some of the main strategies of presentation of this type of product in the grid. In order to do so, we make a historical survey of the soap opera produced and transmitted by Rede Globo, the Brazilian broadcaster that has invested most in dramaturgy and whose works have recognized production quality both in Brazil and abroad. The investigation considered the period from 1965 to 2015, that is, from the inauguration of the network to the present day, taking as reference the titles available on the site Memória Globo. The opening videos were analyzed in light of French semiotics and the results pointed to the recognition of four recurring resources explored: person projections, time, space and thematic procedures - all articulated in such a way as to promote in the public a sense of identification.
\end{abstract}

\section{Keywords}

Soap opera. Vignette. French semiotics.

\section{Autora correspondente}

Jaqueline Esther Schiavoni

jeschiavoni@yahoo.com.br

\section{Como citar}

SCHIAVONI, Jaqueline Esther. Telenovela: elementos identitários em vinheta de abertura. Intexto, Porto Alegre, n. 52, e-86740, jan./dez. 2021. DOI: http://dx.doi.org/10.19132/1807-8583202152.8674

Recebido em 17/09/2018

Aceito em 13/11/2018

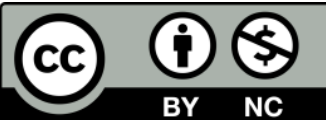

